\title{
Can we speed this up?
}

\section{A perspective on SGMA from outside California}

Ronald C. Griffin, Professor Emeritus, Texas A\&M University, and WaterEcon.com

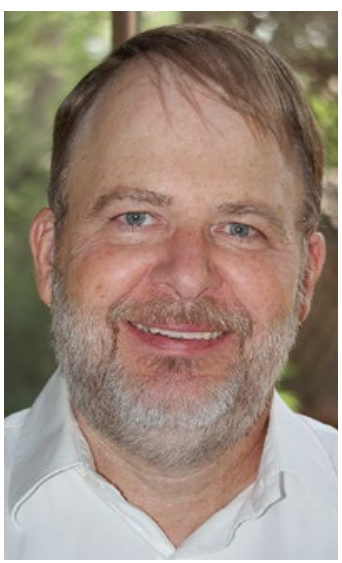

Ronald C. Griffin
A cademic economists such as myself are lucky to live during a time when we can witness a major resource - in this case, water - evolving from state or common property forms to private ones. It's interesting to us! In other resource settings, we have learned that scarcity drives institutional (policy) reform in particular directions. Heightened scarcity reveals the failures of old resource regimes and calls for refinements. According to economic doctrine, the resource management tragedies of nonmarket policies - such as California groundwater law - become so severe that these policies are cast off in favor of private property policy. So, the contested resource is eventually partitioned among its users as a tradable commodity. Because users experience a much fuller slate of their actions' benefits and costs under private property, they practice more efficient stewardship. Absent private property, it is more difficult to achieve various good behaviors in the right amounts (e.g., conservation, investment, technology selection, production, consumption and reallocation).

With groundwater, a move to private property requires the severing of water rights from land rights, quantification (adjudication) of the resultant groundwater rights, and enforcement. Thus, a landowner with a newly created groundwater permit will now own two different things, forever transferrable independently. Good design of water rights, no-trespass enforcement, and efficient oversight of water markets are additionally important elements if things are to progress well.

\section{Where does SGMA point?}

So, what has the 2014 Sustainable Groundwater Management Act (SGMA) done to accelerate this evolution? Let's see. New local groundwater sustainability agencies must develop sustainability plans, and sustainability is defined as the avoidance of six things if any are "significant and unreasonable": lowered groundwater levels, reduced groundwater storage, seawater intrusion, degraded water quality, land subsidence, and depleted surface water. Obviously, all six can accompany groundwater use (two regularly), so what then is reasonable sustainability? One cannot tell by reading the Act. Nice dodge, Legislature. Haven't we learned by now that the political attractiveness of sustainability is its feel-good vagueness, and that reasonable means "let's argue this forever"? What has been achieved by SGMA other than to shift the crucial questions to lower jurisdictions, thus multiplying the burden rather than confronting it and inviting disrespect of the outside-ofjurisdiction effects of depletion?

Of course, this excess employment act for water professionals is welcome in some quarters, and some will speak highly of roles for "stakeholders" and "governance". Water users should always wince when they hear words such as these exulted. Their pockets are being picked by a process that is focused on the process, not the outcome. With regard to moving away from the management failures of state/common property, it would seem that the velocimeter for California groundwater reform is still set on "glacial." The new law allows groundwater sustainability agencies to consider adjudication, to allow transfers of "allocations", and even to allow carryovers of unused allocations (all good!), but 
there are no compulsions or expectations for agencies to uniformly evolve in these directions. Undeveloped funding for these sustainability agencies adds to the inertia.

\section{What would the czar say?}

Considering all this costly "progress", one longs for the czarist state water engineer of the early western states. In California, this dictator would think, "people are pumping too much groundwater", and would think this before things got out of control. The state engineer would have a team study the hydrologies of the various aquifers, and would fund external studies to firm up this knowledge. The czar would set pumping limits at the aquifer level and reject new permit applications that would broach these limits. Initial uncertainties might instill some socially attractive precautions in the announced limits. One hundred percent metering of wells would commence, and the state's demand for compliance would initiate stronger bookkeeping.

The state engineer would know that water supply varies from year to year, so limits and permits would be designed accordingly (for decades now, surface water reservoirs have had successful operating rules to handle variations). Using a seniority system based on prior use (appropriative rights) might make sense to the engineer because it interfaces well with surface water rules, and

Groundwater irrigates a rice field in Yuba County. should not be wastefully stranded. A correlative shares system would be an acceptable alternative. In this system, each permit represents a stated proportion of each year's varying groundwater availability.

The state engineer would be highly concerned about the surface water interactions of groundwater rulings, including required environmental flows, so attention here would be instrumental in framing groundwater limits. Clearly, the engineer's pivotal problem would be whether to set pumping limits at estimated levels of aquifer recharge or at levels involving long-run depletion. For those aquifers with a high degree of surface water interaction and recharge, targeting "no long-run depletion" might be feasible. Otherwise, groundwater use must entail a degree of depletion, and the engineer would be forced to decide on an acceptable rate of depletion for these aquifers. Somewhere in the depths of the SGMA processes these same questions must be answered.

Regardless of the overall limits, trade of groundwater permits would seem sensible to the state engineer. Why not? It's working for surface water and contributes to regional welfare and resilience. The state's compliance division would administer this. Use in excess of one's permit would be seen as a trespass upon other permit holders, and would therefore be penalized at greater than market value. The engineer would know that hydrological knowledge is the weak link in this or any groundwater rule system, so prioritized studies

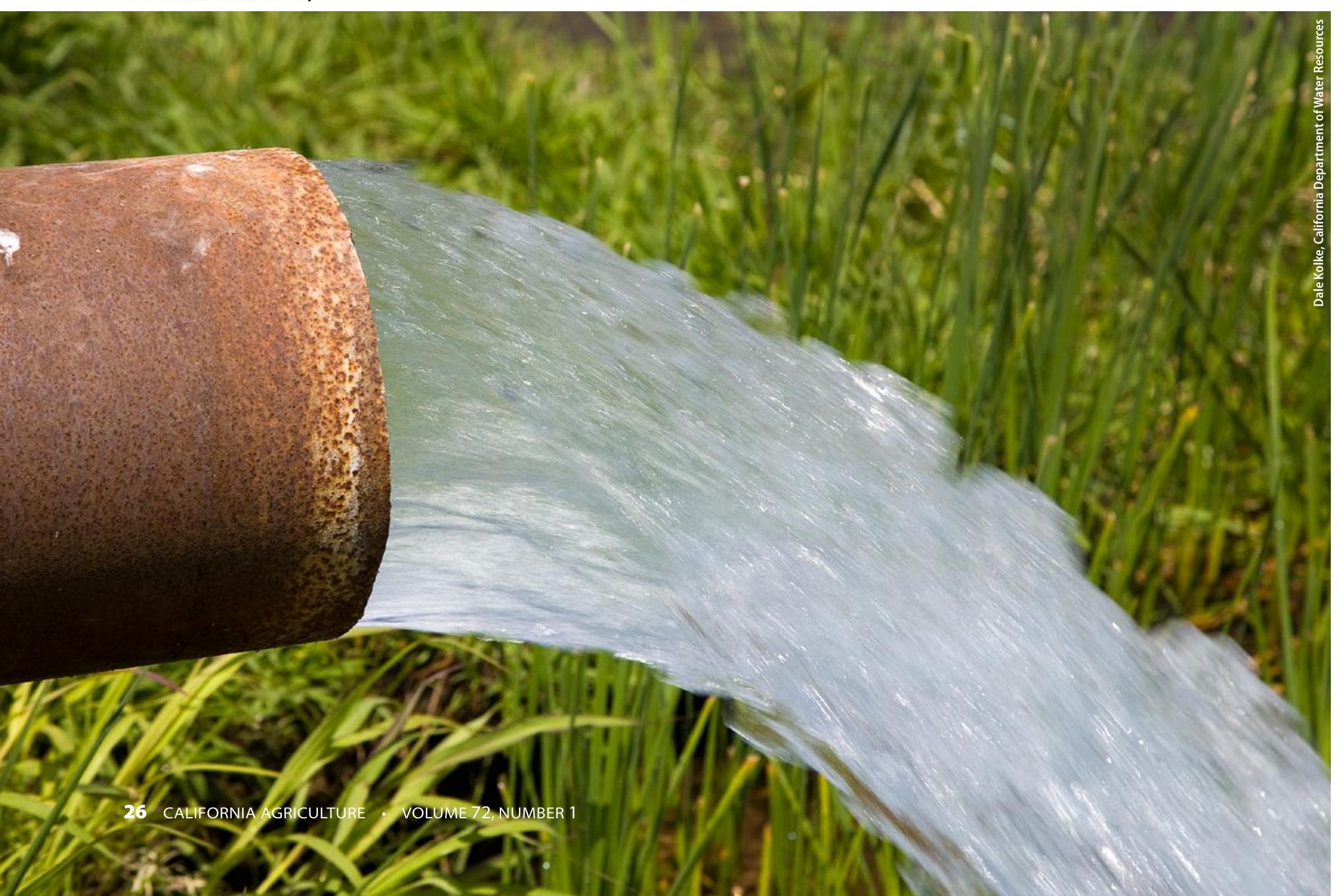


would be continued, limits and permits might be revised over time, and data collection would be a mainstay.

\section{Slow reform has real costs}

But I'm just dreaming. That's because I cannot stop thinking about the enormous costs of water policy reform and poor water policy in California. The cost of the state's water-focused news coverage alone and the reporter time it takes to compile it might exceed Rhode Island's GDP. Just kidding ... perhaps. More disappointing is that all of this news is correlated with the psychological costs felt by a water-worried public saddled with the uncertainty of how badly this will come out and what it is costing them monthly. These are real costs, although they remain unmeasured. Then there's all the political gaming and influence peddling that must be supported. Can the inequities of this political power be any less worrisome than those of economic power accompanying water marketing? Political power is certainly more covert. Even if a city or water district doesn't want to take advantage of its neighbors, it is compelled to hire protection (attorneys, lobbyists, public relations) against other sectors and pumpers. And consider all the miscellaneous consultants, including the new ones needed to wander through the SGMA process. And consider all the effort, from statewide agencies to the local groundwater sustainability agencies that must implement this incomplete Act. All the meetings. All the debates and discussions. Again and again. This will continue because SGMA focused on designing a process rather than directing and guiding an adjudication of groundwater rights.

When legislation such as SGMA is written in California, using malleable PC terms like sustainability and reasonability, are the authors aware that they're fertilizing a water sector of the economy that barely exists in other states? But all government-created jobs are good jobs, right? Never mind that these jobs are siphoning off rewards that water users were supposed to be getting from their state's water resource base. Never mind the diffused tax costs and the injuries to competitiveness. Never mind that the slow pace of reform is another factor failing to signal overpopulation in a state burdened by climate change.

Lest it be forgotten in the mist of implementation, let's try to keep our eyes on an achievable end game. As compared to an idealized water czar or some other expedient path to transferrable groundwater rights, we might try to improve things using nonmarket policies such as nontransferable use regulations (including Governor Jerry Brown's recent conservation edicts), education programs, technology subsidies, and oddly tinkered water rates, but these are partial measures reflecting the limits of individual instruments and the political aims and water acumen of their designers. These nonmarket policies are not commonly robust in the face of drought cycles, unintended consequences, unforeseen options, and other changes. And continuing "change" is the crucial feature of the water scarcity problem. Private property and consequent markets is a more promising strategy.

\section{Private property has been useful}

Westerners are quite familiar with private property in land and even surface water. We have managed developed and developing land this way for a long time, while setting aside large tracts as parks, forests, and other public areas and keeping these tracts out of private hands. Complex economic doctrine formalizes the good sense of this division and is applicable to water. Recall that land has not always been managed this way, and that private property in land was troublesome to achieve. Major U.S. homestead policy of the 1800 s converted public land into private land, thereby clarifying stewardship responsibilities and unlocking private investments and labor. More famously during earlier centuries, thousands of Enclosure Acts in England converted open and shared agricultural lands into private holdings that could support wiser cropping choices and practices. Of course, privately owned land is not locked into agriculture, so it can be shifted to new pursuits as conditions change. Private property in land has been an essential human invention for addressing change.

So too has it recently become useful to move to private property in surface water. The transition of surface water into a private property character is strongly with us now (finally). It has a several-decade jump on similar (hopefully) transformations for groundwater. Major surface water transactions and contracts are crucial tools in the California policy portfolio, as most people know. These tools are predicated on some incarnation (especially quantified shares or prioritized quantities) of enforced, no-trespass, exclusive ownership. Problems such as weak enforcement and organizational ownership of California water, especially by irrigation districts, rather than ownership by individual agents has limited market achievements, but surface water markets have been important.

\section{Can we get there from here?}

With ingenuity, some locales might achieve admirable reform, working within SGMA's messy parameters. The window has closed for installing top-down centralized management à la Idaho and New Mexico, and we cannot wait on a revised SGMA. My outsider's view is that the Act left important opportunities on the table and perpetuated the glacial pace of policy advance.

Maybe groundwater sustainability agencies can struggle forward by emphasizing adjudication and transferability, but shrinking permits down to physical sustainability (zero depletion forever) can be costly, thereby impinging on our social vision of "reasonable sustainability" and adding more delay. CA 